\title{
A Two-Step Crystallization Route for Hierarchical SAPO-34 Molecular Sieves: Unique Structural Features and Catalytic Property for DTO
}

\author{
Guomin Li1, Zhuo Li1 ${ }^{*}$, Xiangzhong Ren², Yan Zhang1, Zhiwen Chen'1, Jianqiang Yu' ${ }^{*}$ \\ ${ }^{1}$ Institute of Green Chemistry and Industrial Catalysis; School of Chemistry and Chemical Engineering, Qingdao University, \\ Qingdao, China \\ ${ }^{2}$ Jinan Institute of Chemical Engineering, Ji'nan, China \\ Email: *lizhuoqd@163.com, *jianqyu@qdu.edu.cn
}

How to cite this paper: Li, G.M., Li, Z., Ren, X.Z., Zhang, Y., Chen, Z.W. and Yu, J.Q. (2019) A Two-Step Crystallization Route for Hierarchical SAPO-34 Molecular Sieves: Unique Structural Features and Catalytic Property for DTO. Materials Sciences and Applications, 10, 302-316. https://doi.org/10.4236/msa.2019.104023

Received: February 8, 2019

Accepted: April 8, 2019

Published: April 11, 2019

Copyright $\odot 2019$ by author(s) and Scientific Research Publishing Inc. This work is licensed under the Creative Commons Attribution International License (CC BY 4.0).

http://creativecommons.org/licenses/by/4.0/

\begin{abstract}
The hierarchical structure can significantly improve the diffusion efficiency of the catalyst and regulate the product distribution. Therefore, the preparation of hierarchical SAPO-34 molecular sieve has been a hot research topic. With Cetyltrimethyl Ammonium Bromide (CTAB) and Diethylamine (DEA) as templates, a two-step crystallization process was employed to synthesize hierarchical SAPO-34 molecular sieves. We found that the aging process is vital for the formation of pure phase SAPO-34. It was investigated the relationship of crystallinity trend and mesoporous content with the crystallization time. The results showed that the prolongation of crystallization time was beneficial to enhance the crystallinity of the molecular sieve, but unfavourable to the retention of mesoporous structure. The formation process of hierarchical SAPO-34 molecular sieve involved agglomeration, disintegration, crystallization, re-agglomeration and growth. The hierarchical SAPO-34 molecular sieve with a satisfactory crystallinity and considerable mesoporous structure could be obtained after 36 hours of crystallization. Moreover, the sample had the most suitable acid strength as well as acid amount. The catalytic activity was investigated by catalytic dimethyl ether (DME) to olefin (DTO) reaction. It revealed that the conversion of DME and the selectivity to olefins over the hierarchical SAPO-34 molecular sieve were significantly enhanced with comparison to that over microporous SAPO-34 molecular sieve. The amount of coke deposition of the hierarchical SAPO-34 molecular sieve (14.2\%) was lower than that over the microporous molecular sieve (16.5\%). Meanwhile, the propylene selectivity of hierarchical SAPO-34 was higher than that of microporous SAPO-34 in the whole reaction. In a word, the hierarchical SAPO-34
\end{abstract}


molecular sieve synthesized in this study showed a longer catalytic life, higher coke deposition resistance and higher propylene selectivity.

\section{Keywords}

CTAB·Adding Step by Step, Hierarchical SAPO-34.DTO, High Propylene Selectivity

\section{Introduction}

Light olefins such as ethylene and propylene have become the backbone of the modern chemical industry. Light olefins are mainly produced by catalytic cracking of petroleum. Due to the decrease of petroleum resources, finding a broad route to prepare light olefins is very urgent. DTO reaction process is a common solution at present. SAPO-34 has attracted the attention of researchers because of its unique pore structure and suitable acid performance, etc. [1]. However, although this unique structure brings high selectivity to olefins, it also brings serious cook deposition [2]. This characteristic restricts its industrial application. Therefore, how to improve the catalytic performance of SAPO-34 molecular sieves has become a hot topic.

For the heterogeneous reaction, diffusion efficiency plays an important role in the reaction performance. The diffusion mode of reactants and products in the micropores adopts configuration diffusion [3], which leads to the secondary reaction of products due to the serious limitation of the mass transfer efficiency. This property of the molecular sieves catalysts is unfavourable for the product selectivity and catalytic lifetime [2] [4]. It has been published that improving the diffusion efficiency can be effectively adopted to optimize the reaction process, modulate the product distribution and increase the catalytic lifetime.

Generally, there are two strategies to improve the diffusion efficiency of catalyst, one of which is to reduce the particle size of the catalyst. The other one is to fabricate the molecular sieves with hierarchical structures.

As for the former one, Li et al. [5] reported the successful synthesis of lamellar SAPO-34 molecular sieves using triethylamine and tetraethyl ammonium hydroxide as dual templates and hexamethylene ammonium hydroxide as auxiliary templates to inhibit the growth of one of the crystal facet and promote the nucleation. This strategy of reducing the particle size of the catalyst can be used to effectively shorten the diffusion pathway, which reduces the coke production rate. $\mathrm{Wu}$ et al. [6] synthesized a nanosheet SAPO-34 by a microwave enhancement process. The effects of crystallization temperature, crystallization time as well as template types on the morphology, the acid content and the acid strength were also studied. However, small particles are difficult to separate and require rigorous preparation conditions.

As reported in the literature, the diffusion rates of gaseous products and reactants are closely dependent on the pore size. It means that the diffusion efficien- 
cy in mesoporous and macroporous materials is much higher than that in microporous materials [3] [7]. In order to construct molecular sieves with hierarchical structure, researchers have explored many meaningful routes [8] [9] [10] [11]. Such as, acid or alkali post-treatment [12] [13], hard template method [14], soft template method [15] [16] [17] [18], solid phase synthesis method [19], in-situ crystallization method [20], and so on. Shen et al. [15] synthesized a hierarchical MFI zeolite with ordered mesoporous. They designed a type of surfactant with diquaternary ammonium groups and an azobenzene group as the template. The strong $\pi-\pi$ intermolecular interaction between azobenzene groups self-assembled the surfactant into the micellar mesostructure. The double quaternary ammonium groups of the surfactant directed the raw materials to the MFI zeolite structure. The matching of the mesoporous structure with the zeolite framework is the key factor for the formation of ordered mesoporous zeolites. Hassan et al. [16] synthesized nanosizedhierarchicalSAPO-34 by using ultrasonic and microwave-assisted aging processes in the hydrothermal synthesis. They investigated the effects of a series of templates on the degrees of mesoporousity. A series of templates include tetradecyldimethyl (3-trimethoxysilylpropyl) ammonium chloride, cetyltrimethyl ammonium bromide, and their combinations. Chen et al. [17] reported a hierarchical SAPO-34 molecular sieve with a weak acidity by using a multifunctional long-chain silicone as the sole source of silicon.

Soft template method has been a common strategy for the preparation of hierarchical molecular sieves. It usually requires expensive organo-silicon, organo-aluminium and organo-phosphorus as raw materials. Its mesoporous templates usually are surfactants. Surfactants form micelles at relatively mild temperatures to produce mesoporous [21]. Its templates used in the synthesis of microporous molecular sieves are generally worked at relatively high crystallization temperatures.

Due to these difference, the phenomena of non-crystallization of raw materials or the formation of various mixtures of crystals and amorphous materials are usually be found in the synthesis of hierarchical molecular sieves by soft template method [22]. To overcome these difficulties, a two-step crystallization process was employed to synthesize hierarchical SAPO-34 molecular sieves. The first step is a low-temperature crystallization to ensure the formation of mesoporous structure, while in the following high-temperature process after the addition of zeolites template, the microporous zeolites structure is formed. The dependence of the hierarchical structure of molecular sieve on the crystallization time was investigated. Moreover, the expensive organo-silicon, organo-aluminium and organo-phosphorus were substituted by the traditional inorganic materials. The dimethyl ether to olefins (DTO) reaction was employed to measure the catalytic performance of the synthesized molecular sieves. It could be found that the amount of coke deposition on the hierarchical SAPO-34 molecular sieve was significantly lower than that over the microporous molecular sieve. Moreover, it is interesting that the selectivity to propylene over the hierarchical SAPO-34 was 
higher than that over microporous SAPO-34 counterpart.

\section{Experiments}

\subsection{Catalyst Preparation}

The hierarchical SAPO-34 zeolites were synthesized by two-step hydrothermal process. The molar ratio of the precursors composition was:

$\mathrm{Al}_{2} \mathrm{O}_{3}: \mathrm{P}_{2} \mathrm{O}_{5}: \mathrm{SiO}_{2}:$ DEA: $\mathrm{H}_{2} \mathrm{O}: \mathrm{CTAB}=1: 0.9: 0.6: 1.6: 50: 0.05$. The typical synthesis procedure is as following: First, mix the pseudo-boehmite (Shandong Aluminum Company, $69.0 \mathrm{wt} \%$ ) with distilled water (Qingdao Chengda Distilled Water Co., Ltd.) and stir until a homogeneous suspension is formed. Then, the phosphoric acid (Sinopharm Chemical Reagent Co., Ltd, 85.0 wt\%) diluted with water was added dropwise into the pseudo-boehmite suspension under rapidly stirred, and kept on stirring for 40 minutes to obtain a mixed gel A. After that, the silica gel (Qingdao Ocean Chemical Co., Ltd., $25.0 \mathrm{wt} \%$ ) was added into the mixed gel A and stirred for another 1 hour to obtain a mixed gel $\mathrm{B}$. Then the gel B was dropped into the dissolve CTAB (Sinopharm Chemical Reagent Co., Ltd, $99 \mathrm{wt} \%$ ) to obtain a mixed gel C. The gel $\mathrm{C}$ was aged at room temperature for $2 \mathrm{~h}$ with stirring, and then transferred into a $100 \mathrm{~mL}$ Teflon-lined stainless steel autoclave to pretreat at $100^{\circ} \mathrm{C}$ for 12 hours (the sample was labeled S-F after calcination). After that, the template for the synthesis of SAPO-34DEA (Sinopharm Chemical Reagent Co., Ltd., 99 wt\%) was added into the autoclave when it was cooled to room temperature. After stirred for 2 hours, the autoclave was re-covered and the mixed gel was crystallized at $180^{\circ} \mathrm{C}$ for 12 hours, 24 hours, 36 hours and 48 hours, respectively. The products were separated and washed, and calcined at $550^{\circ} \mathrm{C}$ for 5 hours to obtain a series of hierarchical SAPO-34 molecular sieves, which were labeled as S-12, S-24, S-36 and S-48 samples.

In contrast, microporous SAPO-34 molecular sieve (labeled S-W) was synthesized by a conventional hydrothermal synthesis method according to the literature [23]. Samples synthesized by one-step crystallization route were labeled S-O. One-stepcrystallization route has the same method to obtain the aged gel C, and then the aged gel $\mathrm{C}$ was added into DEA and stirred for 2 hours to obtain the gel D. Finally, the gel D was transferred into the autoclave to crystallize at $180^{\circ} \mathrm{C}$ for 48 hours.

\subsection{Catalyst Characterization}

The crystal phase structure and crystallinity of the sample were characterized by X-ray diffractometer (DX-2700, China, Dandong Haoyuan Instrument Co., Ltd.). Test conditions: room temperature, $\mathrm{Cu}$ target, $\mathrm{Ka}$ source, tube voltage 40 $\mathrm{kV}$, tube current $30 \mathrm{~mA}$, scan range $2 \theta=5^{\circ}-40^{\circ}$. The morphologies of the samples were observed using a scanning electron microscope (JSM-6390LV, JEOL, Japan). The $\mathrm{N}_{2}$ adsorption-desorption isotherm, specific surface area, and pore volume of the samples were measured on a fully automatic specific surface area and porosity analyzer (ASAP 2460, Micron, USA). Prior to the measurement, 
the samples were degassed under vacuum at $300^{\circ} \mathrm{C}$ for 4 hours. The coke amount for the used catalyst was analyzed by a thermogravimetric analyzer (TG209F3, Germany, NETZSCH). The coked catalyst was heated from $50^{\circ} \mathrm{C}$ to $800^{\circ} \mathrm{C}$ with a heating rate of $10^{\circ} \mathrm{C} / \mathrm{min}$ and air flow rate of $100 \mathrm{~mL} / \mathrm{min}$.

The acidity of the sample was measured by temperature-programmed desorption of ammonia $\left(\mathrm{NH}_{3}\right.$-TPD) on a chemisorption analyzer (FINETEC FINSORB-3010). Typically, the sample was first pretreated at $200^{\circ} \mathrm{C}$ for $30 \mathrm{~min}$ with a ramp rate of $20^{\circ} \mathrm{C} / \mathrm{min}$ in the helium flow of $20 \mathrm{~mL} / \mathrm{min}$. When the temperature was dropped to $50^{\circ} \mathrm{C}$, the $5 \% \mathrm{NH}_{3} / 95 \% \mathrm{He}$ was introduced to adsorbe on the catalyst for $40 \mathrm{~min}$ until saturation. After that, it was purged with helium at $20 \mathrm{~mL} / \mathrm{min}$ for $1 \mathrm{~h}$, followed by increasing temperature to $800^{\circ} \mathrm{C}$ at a rate of $20^{\circ} \mathrm{C} / \mathrm{min}$.

\subsection{Catalytic Performance}

The catalytic performance of these samples for DTO reaction was measured with a fixed bed reactor. In brief, $2 \mathrm{~g}$ catalyst (20 - 40 mesh) was charged into the reactor $(550 \mathrm{~mm} \times 10 \mathrm{~mm})$, and activated at $450^{\circ} \mathrm{C}$ for 1 hour under a nitrogen ( $50 \mathrm{~mL} / \mathrm{min}$ ) atmosphere prior to reaction. Subsequently, DME gas with WHSV $=0.725 \mathrm{~h}^{-1}$ was introduced into the reactor for $6 \mathrm{~h}$, when cooling to $400^{\circ} \mathrm{C}$. The reaction product was detected on-line by Shimadzu Corporation GC-2014C gas chromatography. After the reaction stopped, the catalyst was cooled to room temperature under nitrogen, and the used catalyst was subjected to coke deposition analysis by a thermos-gravimetric analyzer.

\section{Results and Discussions}

\subsection{Structural Features of the Catalysts}

Figure 1(a) reveals that the S-O is a mixture of SAPO-34 and SAPO-5 molecular sieve. Moreover, the S-48 is the pure SAPO-34 molecular sieve. This result indicates that the two-step method can solve the problem that mesoporous template and microporous template cannot collaborate to synthesize hierarchical SAPO-34 molecular sieves. The XRD diffraction pattern of S-F shows that the first step is to polymerize the raw materials into the aluminum phosphate under the function of CTAB.

From Figure 1(b) we can know: the S-12 and S-24 samples showed characteristic peaks of CHA structure and a peak cluster composed of three peaks at about $21^{\circ}$, which is the aluminum phosphate. This is because some of the raw materials have not yet been converted into crystals due to the short crystallization time, and this part of the raw material forms the dense phase $\mathrm{AlPO}_{4}$. The crystallinity of SAPO-34 enhanced with the improvement of crystallization time from 24 hours to 36 hours. After 36 hours of crystallization, the $\mathrm{AlPO}_{4}$ peaks disappeared, this indicates that $\mathrm{AlPO}_{4}$ has been completely converted to SAPO-34. After 48 hours of crystallization, the diffraction peak of S- 48 is obviously higher than that of S-36. This is probably due to the existence of hierarchical 

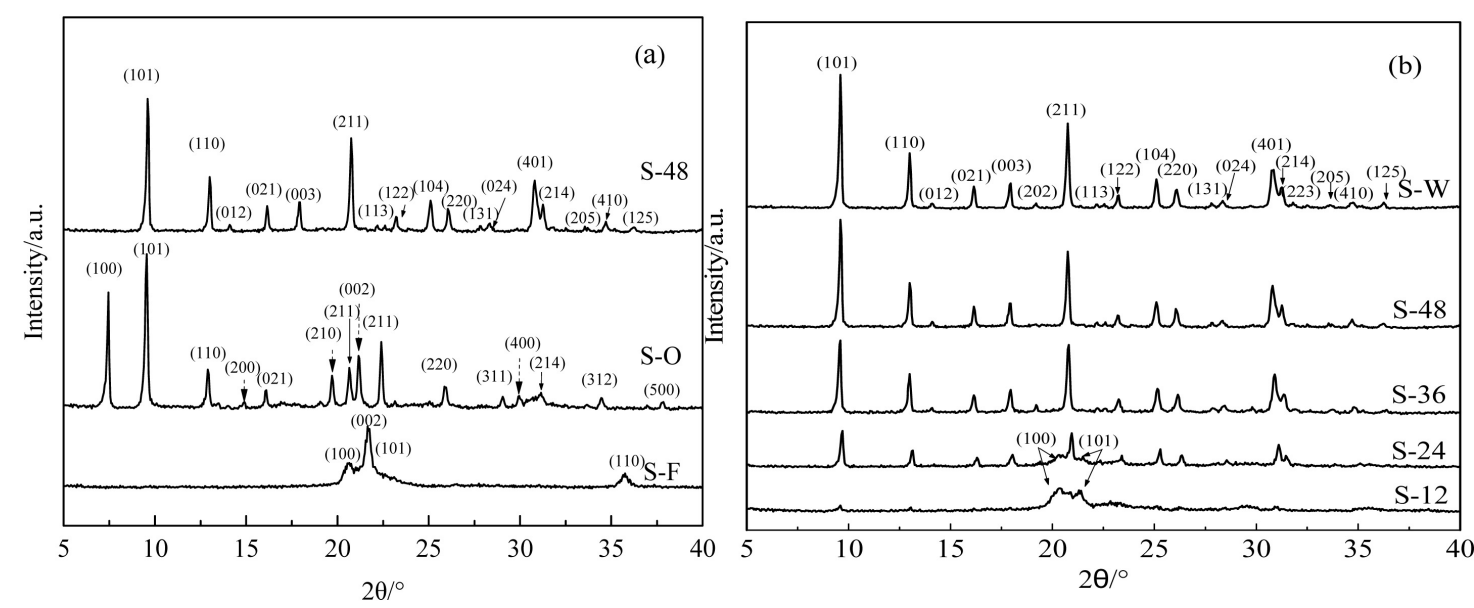

Figure 1. XRD patterns of microporous SAPO-34 and hierarchical SAPO-34 synthesized with different method and crystallization time. (a) Samples synthesized by different method; (b) The hierarchical SAPO-34 synthesized with different crystallization time.

pores makes defects in crystals, which leads the diffraction peak of S-36 lower than that of S-48.

The hierarchical pores of S-36 were supported by CTAB micelles. These micelles could be destroyed by exposing to the high temperature for along time [21]. The crystals containing hierarchical structure were gradually transformed into more stable microporous crystals with the crystallization time further extended to 48 hours. That results in the obviously enhanced diffraction peak for S-48, which is also supported by the BET results. S- 48 still has some defects, so the peak of S-48 is lower than that of S-W.

\subsection{Morphology of Catalysts}

Figure 2(a) is the microporous SAPO-34 molecular sieve with regular cubic structure synthesized by conventional hydrothermal method. From Figure 2(b) to Figure 2(f), the formation process of the hierarchical SAPO-34 zeolite was recorded. Figure 2(b) shows that the S-F is spherical agglomerates, which were formed by the initial polymerization of raw materials under the function with CTAB. Figure 2(c) shows that the S-12 sample maintained a spherical particle, and the effect of DEA on its morphology has not yet been demonstrated. Combined with the XRD results, we can know that the nucleation could not be generated unless the existence of DEA. This is the initial stage of crystallization. The initial spherical structure has been destroyed after 24 hours of crystallization and then a large number of fragments were formed due to the existence of DEA, as shown in Figure 2(d). As the extending of crystallization time, these fragments had become crystals or participated in the crystallization process. It can be got from Figure 2(e) that the amorphous particles had disappeared and turned into crystals after 36 hours, which was consistent to the XRD results. Figure 2(f) shows that the macro-morphology of SAPO-34 zeolite changed little when the crystallization time was extended from 36 hours to 48 hours.

It can be inferred that the raw materials formed spherical aggregates under the 


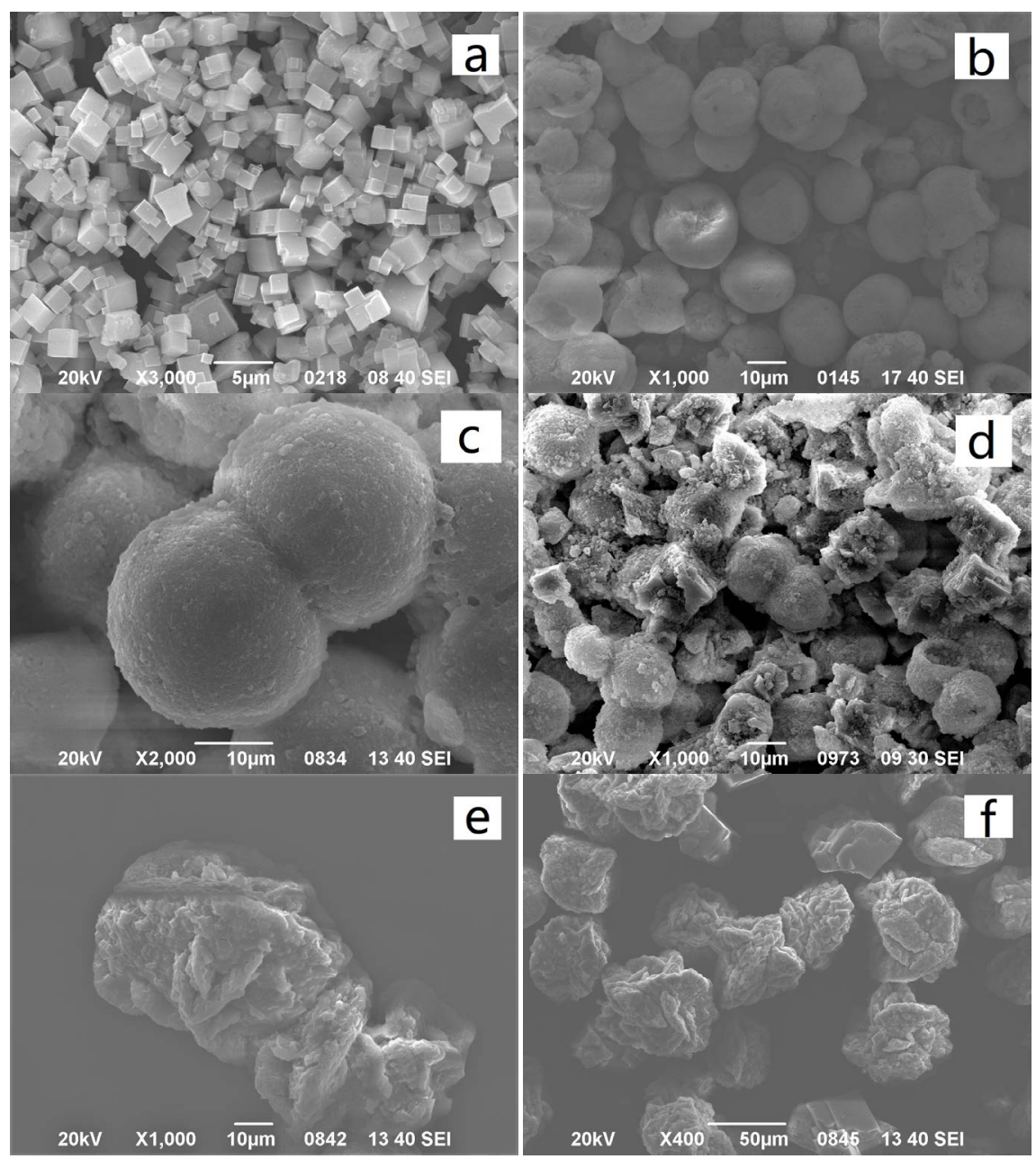

Figure 2. SEM images of microporous SAPO-34 and hierarchical SAPO-34 synthesized with different crystallization time. (a) S-W; (b) S-F; (c) S-12; (d) S-24; (e) S-36; (f) S-48.

function of $\mathrm{CTAB}$ in the first step. These spherical aggregates contained $\mathrm{CTAB}$ micelles, and the micelles formed the hierarchical structure of spherical aggregates. Then the spherical agglomerates were destroyed, disintegrated and crystallized under the effect of DEA. From the XRD results, we can know it is difficult to obtain pure SAPO-34 without the aggregate in the first step. The aggregate generated in the first step will be disintegrated in the subsequent process, so the shape of the aggregate is not the key for this experiment. CTAB could improve the viscosity of crystalline system, which promoted the agglomeration and growth of minute crystals. Therefore, the large SAPO-34 molecular sieve with hierarchical structure was formed. The mesoporous structure assembled by CTAB was gradually destroyed and transformed into the microporous structure after a longer crystallization time. This change belongs to the variation of microstructure (supported by BET results) instead of the change of macro-morphology.

\subsection{Textural Characterization}

All the four samples prepared by adding CTAB show H4 hysteresis loops in type 
IV isotherm according to the IUPAC, which was obtained by the $\mathrm{N}_{2}$ adsorption-desorption characterization (Figure 3). Figure $3(\mathrm{~b})$ is an amplified view of the samples. Figure 3(a) reveals that the starting point of the hysteresis loops is between 0.4 and 0.5 relative pressure, indicating the presence of mesoporous structure. The decreasing trend of hysteresis loop of samples from S-12 to S-48 indicates the gradual destroy of the mesoporous structure with the prolongation of crystallization time. This can also be verified by the variation of average poresize (shown in Table 1).

From the Table 1, it can be seen that the specific surface area of hierarchical molecular sieves is slightly smaller than that of microporous molecular sieves due to the low crystallinity of hierarchical molecular sieves (listed in Table 1). Meanwhile, it can be directly observed that the $S_{\text {micr }}$ decreased and the $S_{\text {ext }}$ increased with the prolongation of crystallization time from $24 \mathrm{~h}$ to $36 \mathrm{~h}$, which suggests the dissolution of some small crystal particles and the accumulation of some small crystal particles to bulk crystals. S- 48 has the small hysteresis loop with the small $S_{\text {ext }}$ its $S_{\text {micr }}$ is similar to S-W, while its average pore size is much larger than that of S-W. These all indicate S- 48 contains a little of stacking holes, which consist with our previous conjecture.

Table 1. Texture properties of each sample.

\begin{tabular}{|c|c|c|c|c|c|c|c|c|c|c|}
\hline \multirow[t]{2}{*}{ Sample } & \multicolumn{3}{|c|}{$\begin{array}{c}\text { BET Surface Area } \\
\qquad A /\left(\mathrm{m}^{2} \cdot \mathrm{g}^{-1}\right)\end{array}$} & \multicolumn{3}{|c|}{ Pore Volume $V /\left(\mathrm{m}^{3} \cdot \mathrm{g}^{-1}\right)$} & \multirow{2}{*}{$\begin{array}{c}\text { Average } \\
\text { Pore Size } \\
\text { d/nm }\end{array}$} & \multicolumn{3}{|c|}{ acid amount } \\
\hline & $S_{\text {total }}$ & $S_{\text {micr }}$ & $S_{\text {ext }}$ & $V_{\text {total }}$ & $V_{\text {micr }}$ & $V_{\text {ext }}$ & & $A_{W}$ & $A_{s}$ & $A_{t}$ \\
\hline S-12 & 150 & 2 & 148 & 0.575 & 0.000 & 0.575 & 7.25 & 9040 & 796 & 9836 \\
\hline S-24 & 538 & 479 & 59 & 0.361 & 0.180 & 0.181 & 5.83 & 12,268 & 5285 & 17,553 \\
\hline S-36 & 551 & 467 & 84 & 0.255 & 0.187 & 0.068 & 3.18 & 15,597 & 8829 & 24,426 \\
\hline S- 48 & 736 & 725 & 11 & 0.286 & 0.263 & 0.023 & 3.08 & 16,354 & 8220 & 24,574 \\
\hline S-W & 796 & 796 & 0 & 0.287 & 0.286 & 0.001 & 1.44 & 13,730 & 8500 & 22,230 \\
\hline
\end{tabular}

$S_{\text {total }}:$ Total specific surface area, $S_{\text {micr }}:$ Micropore specific surface area, $S_{\text {ext }}:$ Specific surface area outside the micropore, $V_{\text {total }}$ : Total pore volume, $V_{\text {micr: }}$ Micropore volume, $V_{\text {ext }}$ pore volume outside the micropore volume, $A_{w}$ Integral area of weak acid peak, $A_{s}$ : Integral area of strong acid peak, $A_{i}$ total area.
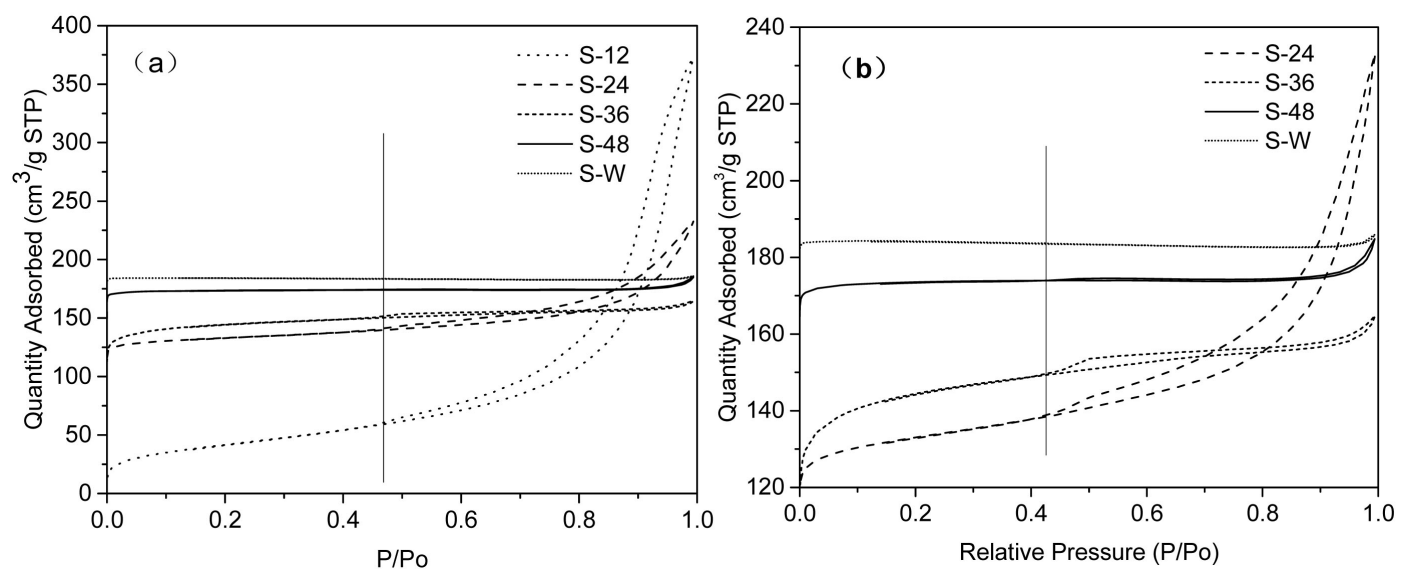

Figure 3. Nitrogen adsorption-desorption isotherms of microporous SAPO-34 and hierarchical SAPO-34 synthesized with different crystallization time. (a) All samples; (b) Fractionated gain for S-24, S-36, S-48 and S-W. 


\section{4. $\mathrm{NH}_{3}$-TPD Characterization}

The acidity of catalysts shows a vital impact on the selectivity of products and catalyst lifetime in the catalytic dimethyl ether (methanol) to olefins. The acid strength and acid amount of the present catalysts were determined by using $\mathrm{NH}_{3}$-TPD. The results are shown in Figure 4. It is observed that all the samples showed characteristic peak of weak acid center $\left(\sim 200^{\circ} \mathrm{C}\right)$ and a strong acid center $\left(\sim 500^{\circ} \mathrm{C}\right)$. The acid amount increased gradually with the crystallization time extending to 36 hours, while the total acid amount varied a little after 36 hours. The less acid amount of S-24 than S-36 was attributed to the lower crystallinity. With the further crystallization up to 48 hours, more silicon enter the framework due to the substitution mechanism [24], which might cause some small silicon islands connect together and result in the reduced number of silicon hydroxyl and slightly decrease of acid amount.

According to the crystallization rule of SAPO-34, most silicon made up the framework of molecular sieve by directly participating in the process of nucleation and crystal growth, while a small amount of silicon entered by substituting mechanism in the later stage of crystallization [24] [25]. Combined with XRD results, it found that the nucleation and growth of zeolite were in progress before $36 \mathrm{~h}$ and the crystallization was progressed after 36 hours under our synthetic conditions. Silicon mainly joined the framework by the substitution mechanism after 36 hours, and it produced some silicon islands and enhanced the acidity of the zeolites. So the acidity of S-48 is obviously stronger than that of S-36. The acid strength of S-W with crystallization time for 48 hours is similar to that of S-36, which can be attributed to the fact that CTAB increases the viscosity of crystallization system and speeds up the growth of molecular sieves. It is reported that the crystal size affects the acidity [26]. Therefore, we believe that the enhancement of S-48 acidity is not only caused by the increase in particle size,

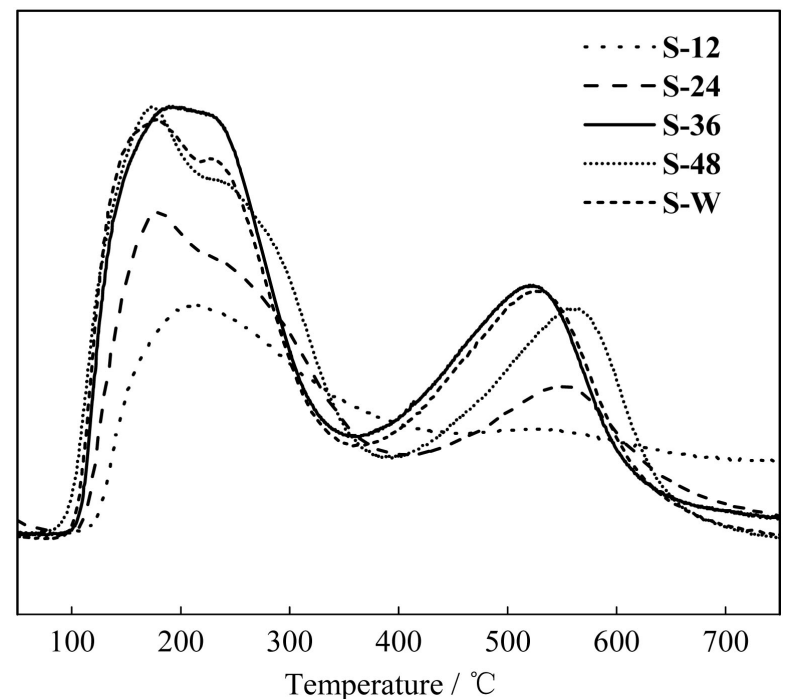

Figure 4. $\mathrm{NH}_{3}$-TPD curve of microporous SAPO-34 and hierarchical SAPO-34 synthesized with different crystallization time. 
but also due to more silicon enters the crystal as the crystallization time increases [24].

\subsection{Catalytic Performance}

The results of the respective catalysts in the DTO reaction are showed in Figure 5. It shows that S-24 and S- 48 were quickly deactivation after 1 hour of reaction and almost all the catalytic activity has been lost after 4 hours of reaction. The conversion rate of DME on S-36 was $77.3 \%$ after 4 hours of reaction, while that on S-W was only $27.6 \%$. Therefore, the catalytic stability of S-36 is better than that of S-W.

Coke deposition is considered to be the main reason for the deactivation of SAPO-34 molecular sieves [27] [28]. The coke amount of the catalysts with time on stream for 6 hours was measured by thermos gravimetric analysis. The results are listed in Table 2. The results show that the coke content in S-24 is the lowest (4.37\%), but it deactivated quickly. This is due to the poor crystallinity of S-24 and the lack of catalytic activity of dense phase $\mathrm{AlPO}_{4}$, which can be confirmed by the above characterizations.

According to the report in the literature [10] [26] [29] [30], the MTO reaction requires reasonable cooperation between strong acid center and weak acid center, among which the strong acid sites are beneficial for the coke deposit. S-48 has more weak acid content than S-36, but its strong acid center is enhanced and

Table 2. DME conversion and coke deposition amount of each sample.

\begin{tabular}{ccccc}
\hline Simple & S-W & S-24 & S-36 & S-48 \\
\hline Time on stream/h & 6 & 6 & 6 & 6 \\
DME conversion/\% & 4.4 & 1.8 & 16.5 & 1.0 \\
Coke/\%, $\left(\mathrm{g}^{-1}\right.$ cat $_{\text {cat }}$ & 16.5 & 4.4 & 14.2 & 9.5 \\
\hline
\end{tabular}

Reaction conditions: $\mathrm{T}=400^{\circ} \mathrm{C}, \mathrm{WHSV}=0.725 \mathrm{~h}^{-1}$.

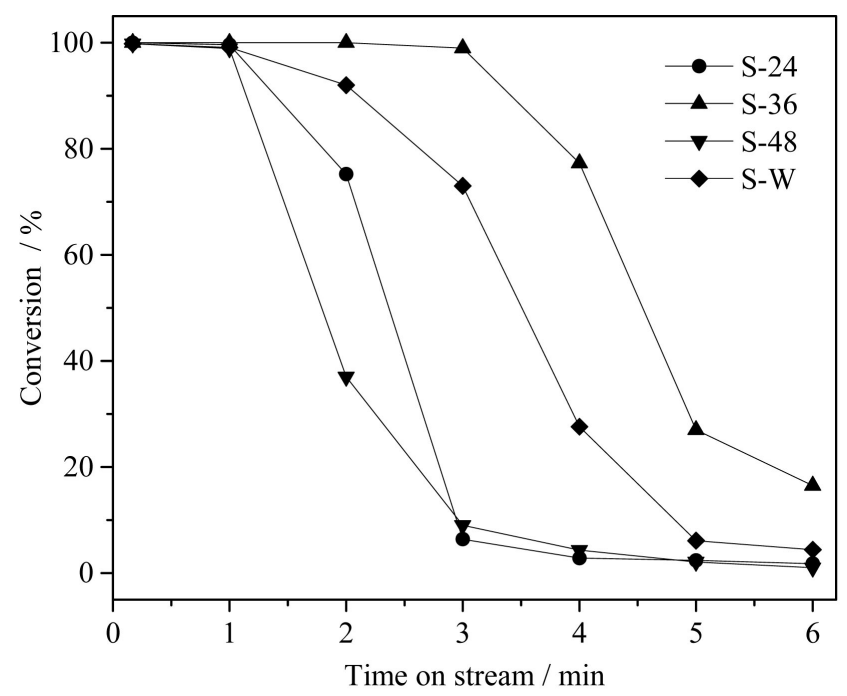

Figure 5. Catalytic performance of each sample for the DTO reaction. Reaction conditions: $\mathrm{T}=400^{\circ} \mathrm{C}, \mathrm{WHSV}=0.725 \mathrm{~h}^{-1}$. 
its strong acid content is reduced than S-36 (in Table 1). Therefore, we believe that S-36 has the most suitable acid strength and acid content. The internal hierarchical structure could greatly increase the diffusion of the product to suppress the coke formation. S- 48 has stronger acid centers than S-36 and S-W. Its crystal size is large with few mesoporous in it. These characteristics make it easy to deposit coke. But its coke content (9.53\%) is lower than that of S-36 (14.19\%) and S-W (16.51\%). This is because it is easy to deposit coke, which causes rapid blockage of superficial pores and makes the inner active centers difficult to participate in the reaction. This reduces the utilization rate of active sites while reducing the production of coke. S-36 and S-W have similar acid environment, and the crystal size of S-36 is much larger than S-W, but the coke content of S-36 (14.19\%) is much lower than S-W (16.51\%), and the conversion of DME is also much higher than the latter. This result can be attributed to the fact that the hierarchical structure can effectively increase the diffusion efficiency of products, inhibit the occurrence of secondary reactions and thus reduce the production of coke.

The product distribution of each sample is showed in Table 3. The methane content in the product increased greatly, and the conversion of dimethyl ether decreased greatly on S-24 and S-48. It indicated that they have been seriously inactivated. Although the crystal size of S-36 is much larger than S-W, the introduction of hierarchical holes in the crystal can significantly enhance the product diffusion efficiency, so the selectivity of olefins on S-36 (86.64\%) is higher than that on S-W (84.02\%). The good diffusion efficiency can effectively suppress the occurrence of the secondary reaction, such as the hydrogen-transfer reaction [31]. This can also effectively inhibit the formation of alkanes while increasing the selectivity of the light olefins. It is known that the increase of diffusion efficiency is more advantageous to long chain products. And the structure of SAPO-34 determines there are very few $\mathrm{C}^{4+}$ products. So the increase of propylene selectivity is most obvious on S-36. Table 3 shows that S-36 (51.29\%) has a $0.24 \%$ increasement in the ethylene selectivity over S-W $(51.05 \%)$ and the propylene selectivity increased from $32.97 \%$ to $35.35 \%$ and by $2.38 \%$. In conclusion, the hierarchical SAPO-34 synthesized by this method has higher catalytic stability, higher selectivity for low olefins and higher selectivity for propylene

Table 3. The product distribution of each sample.

\begin{tabular}{ccccccccc}
\hline \multirow{8}{*}{ Sample } & \multicolumn{7}{c}{ Selectivity/\% } & \\
\cline { 2 - 7 } & $\mathrm{CH}_{4}$ & $\mathrm{C}_{2} \mathrm{H}_{6}$ & $\mathrm{C}_{2} \mathrm{H}_{4}$ & $\mathrm{C}_{3} \mathrm{H}_{8}$ & $\mathrm{C}_{3} \mathrm{H}_{6}$ & $\mathrm{C}_{4+}$ & $\mathrm{C}_{2=}+\mathrm{C}_{3=}$ & $\mathrm{C}_{3=} / \mathrm{C}_{2=}$ \\
\hline $\mathrm{S}-24$ & 30.58 & 3.62 & 39.43 & 4.65 & 18.84 & 2.89 & 58.27 & 0.48 \\
$\mathrm{~S}-36$ & 1.95 & 1.35 & 51.29 & 2.71 & 35.35 & 7.35 & 86.64 & 0.67 \\
$\mathrm{~S}-48$ & 15.54 & 4.28 & 45.57 & 4.98 & 23.59 & 6.05 & 69.16 & 0.52 \\
$\mathrm{~S}-\mathrm{W}$ & 2.79 & 2.29 & 51.05 & 3.25 & 32.97 & 7.65 & 84.02 & 0.65 \\
\hline
\end{tabular}

Reaction conditions: $\mathrm{T}=400^{\circ} \mathrm{C}$, WHSV $=0.725 \mathrm{~h}^{-1}, \mathrm{t}=4 \mathrm{~h}$. 
than the microporous SAPO-34. Its catalytic performance is superior to that of microporous SAPO-34 zeolite.

\section{Conclusion}

Hierarchical SAPO-34 zeolite was successfully synthesized from conventional raw materials and templates. The characterization results showing the crystallization process of SAPO-34 synthesized by this method were as follows: The raw materials formed relatively stable spherical agglomerates with hierarchical structure under the function of CTAB. Then the spherical agglomerates were broken and crystallized under the function of DEA. Then, the hierarchical SAPO-34 molecular sieves were formed by stacking growth under the combined function of the two. In this process, the unstable mesoporous structure will transform into microporous structure at high crystallization temperature with the prolongation of crystallization time. Therefore, it is necessary to control the crystallization time to obtain the ideal hierarchical structure. Furthermore, it was found that the hierarchical SAPO-34 molecular sieves with more hierarchical pores and moderate strength of strong acid centers were obtained at 36 hours of crystallization time. These properties were favorite to the DTO reaction showing in the low coke deposition, high propylene selectivity and long catalytic lifetime. This experiment will provide a new clue for the synthesis of hierarchical SAPO-34 molecular sieves, which is favorable to the application of SAPO-34 in industry.

\section{Acknowledgements}

This work was financially supported by the National Natural Science Foundation of China (No.21706140) and the Shandong Provincial Natural Science Foundation of China (ZR2017BB039).

\section{Conflicts of Interest}

The authors declare no conflicts of interest regarding the publication of this paper.

\section{References}

[1] Wilson, S. and Barger, P. (1999) The Characteristics of SAPO-34 Which Influence the Conversion of Methanol to Light Olefins. Microporous and Mesoporous Materials, 29, 117-126. https://doi.org/10.1016/S1387-1811(98)00325-4

[2] Chen, D., Moljord, K. and Holmen, A. (2012) A Methanol to Olefins Review: Diffusion, Coke Formation and Deactivation on SAPO Type Catalysts. Microporous and Mesoporous Materials, 164, 239-250. https://doi.org/10.1016/j.micromeso.2012.06.046

[3] Kustova, M.Y., Hasselriis, P. and Christensen, C.H. (2004) Mesoporous MEL Type Zeolite Single Crystal Catalysts. Catalysis Letters, 96, 205-211. https://doi.org/10.1023/B:CATL.0000030122.37779.f4

[4] Hereijgers, B.P.C., Bleken, F., Nilsen, M.H., Svelle, S., Lillerud, K.P., Bjørgen, M., 
Weckhuysen, B.M. and Olsbye, U. (2009) Product Shape Selectivity Dominates the Methanol-to-Olefins (MTO) Reaction over H-SAPO-34 Catalysts. Journal of Catalysis, 264, 77-87. https://doi.org/10.1016/j.jcat.2009.03.009

[5] Li, X.F., Wang, P., Di, C.Y., Li, Z.H., Gao, M. and Dou, T. (2016) The Preparation of Layered SAPO-34 Molecular Sieve with Double Ammonium Template and Its Catalytic Performance for MTO Reaction. Acta Petrolei Sinica (Petroleum Processing Section), 32, 1099-1105.

[6] Wu, L., Liu, Z.Y., Qiu, M.H., Yang, C.G., Xia, L., Liu, X. and Sun, Y.H. (2014) Morphology Control of SAPO-34 by Microwave Synthesis and Their Performance in the Methanol to Olefins Reaction. Reaction Kinetics, Mechanisms and Catalysis, 111, 319-334. https://doi.org/10.1007/s11144-013-0639-1

[7] Pérez-Ramírez, J., Christensen, C.H., Egeblad, K., Christensen, C.H. and Groen, J.C. (2008) Hierarchical Zeolites: Enhanced Utilisation of Microporous Crystals in Catalysis by Advances in Materials Design. Chemical Society Reviews, 37, 2530-2542. https://doi.org/10.1039/b809030k

[8] Fang, Y.M. and Hu, H.Q. (2006) An Ordered Mesoporous Aluminosilicate with Completely Crystalline Zeolite Wall Structure. JACS, 128, 10636-10637. https://doi.org/10.1021/ja0611821

[9] Na, K., Jo, C., Kim, J., Cho, K., Jung, J., Seo, Y., Messinger, R.J., Chmelka, B.F. and Ryoo, R. (2011) Directing Zeolite Structures into Hierarchically Nanoporous Architectures. Science, 333, 328-332. https://doi.org/10.1126/science.1204452

[10] Sun, Q.M., Wang, N., Bai, R.S., Chen, X.X. and Yu, J.H. (2016) Seeding Induced Nano-Sized Hierarchical SAPO-34 Zeolites: Cost-Effective Synthesis and Superior MTO Performance. Journal of Materials Chemistry A, 4, 14978-14982. https://doi.org/10.1039/C6TA06613E

[11] Chen, L., Xue, T., Zhu, S.Y. and Wang, Y.M. (2015) One-Step Synthesis of Hierarchical ZSM-5 Zeolite Microspheres Using Alkyl-Polyamines as Single Templates. Acta Physico-Chimica Sinica, 31, 181-188.

[12] Ren, S., Liu, G.J., Wu, X., Chen, X.Q., Wu, M.H., Zeng, G.F., Liu, Z.Y. and Sun, Y.H. (2017) Enhanced MTO Performance over Acid Treated Hierarchical SAPO-34. Chinese Journal of Catalysis, 38, 123-130. https://doi.org/10.1016/S1872-2067(16)62557-3

[13] Wang, Y.L., Li, X.L., Ma, H., Zhang, H., Jiang, Y., Wang, H., Li, Z. and Wu, J.H. (2017) Effect of the Desilication of H-ZSM-5 by Alkali Treatment on the Catalytic Performance in Fischer-Tropsch Synthesis. Reaction Kinetics, Mechanisms and Catalysis, 120, 775-790. https://doi.org/10.1007/s11144-016-1120-8

[14] Varzaneh, A.Z., Towfighi, J. and Sahebdelfar, S. (2016) Carbon Nanotube Templated Synthesis of Metal Containing Hierarchical SAPO-34 Catalysts: Impact of the Preparation Method and Metal Avidities in the MTO Reaction. Microporous and Mesoporous Materials, 236, 1-12. https://doi.org/10.1016/j.micromeso.2016.08.027

[15] Shen, X.F., Mao, W.T., Ma, Y.H., Xu, D.D., Wu, P., Terasaki, O., Han, L. and Che, S.A. (2017) A Hierarchical MFI Zeolite with a Two-Dimensional Square Mesostructure. Angewandte Chemie International Edition, 57, 724-728. https://doi.org/10.1002/anie.201710748

[16] SharifiPajaie, H. and Taghizadeh, M. (2016) Methanol Conversion to Light Olefins over Surfactant-Modified Nanosized SAPO-34. Reaction Kinetics, Mechanisms and Catalysis, 118, 701-717. https://doi.org/10.1007/s11144-016-1023-8

[17] Chen, L., Wang, R.W., Ding, S., Liu, B.B., Xia, H., Zhang, Z.T. and Qiu, S.L. (2010) Synthesis and Characterization of SAPO-34-H (Hierarchical). Chemical Journal of 
Chinese Universities, 31, 1693-1696.

[18] Jin, L.J., Liu, S.B., Xie, T., Wang, Y.T., Guo, X.H. and Hu, H.Q. (2014) Synthesis of Hierarchical ZSM-5 by Cetyltrimethylammonium Bromide Assisted Self-Assembly of Zeolite Seeds and Its Catalytic Performances. Reaction Kinetics, Mechanisms and Catalysis, 113, 575-584. https://doi.org/10.1007/s11144-014-0743-x

[19] Jin, Y.Y., Sun, Q., Qi, G.D., Yang, C.G., Xu, J., Chen, F., Meng, X.J., Deng, F. and Xiao, F.S. (2013) Solvent-Free Synthesis of Silicoaluminophosphate Zeolites. Angewandte Chemie International Edition, 52, 9172-9175. https://doi.org/10.1002/anie.201302672

[20] Zhu, J., Cui, Y., Wang, Y. and Wei, F. (2009) Direct Synthesis of Hierarchical Zeolite from a Natural Layered Material. Chemical Communications, 45, 3282-3284. https://doi.org/10.1039/b902661d

[21] Zhao, D.Y., Wan, Y. and Zhou, W.Z. (2016) Ordered Mesoporous Molecular Sieve Materials. Higher Education Press, Beijing.

[22] Karlsson, A., Stöcker, M. and Schmidt, R. (1999) Composites of Micro- and Mesoporous Materials: Simultaneous Syntheses of MFI/MCM-41 like Phases by a Mixed Template Approach. Microporous and Mesoporous Materials, 27, 181-192. https://doi.org/10.1016/S1387-1811(98)00252-2

[23] Zhao, D.P., Zhang, Y., Li, Z., Wang, Y. and Yu, J.Q. (2017) Synthesis of SAPO-18/34 Intergrowth Zeolites and Their Enhanced Stability for Dimethyl Ether to Olefins. RSC Advances, 7, 939-946. https://doi.org/10.1039/C6RA25080G

[24] Liu, H.X., Xie, Z.K., Zhang, C.F., Chen, Q.L. and Yang, Y.Q. (2003) Effects of Silicon Source Content and Crystallization Time on the Structure and Catalytic Performance of SAPO-34 Molecular Sieve. Chinese Journal of Inorganic Chemistry, 19, 240-246.

[25] Tan, J., Liu, Z.M., He, C.Q., Liu, X.C., Han, X.W., Zhai, R.S. and Bao, X.H. (1999) Method and Mechanism of Si Incorporation into Lattice of SAPO-34 Molecular Sieve. Chinese Journal of Catalysis, 20, 227-232.

[26] He, C.Q., Liu, Z.M., Yang, L.X. and Cai, G.Y. (1995) Adjusting the Crystallite Size of SAPO-34 Molecular Sieve by the Dual Templatte Method. Chinese Journal of Catalysis, 16, 33-37.

[27] Qi, G.Z., Xie, Z.K., Yang, W.M., Zhong, S.Q., Liu, H.X., Zhang, C.F. and Chen, Q.L. (2007) Behaviors of Coke Deposition on SAPO-34 Catalyst during Methanol Conversion to Light Olefins. Fuel Processing Technology, 88, 437-441. https://doi.org/10.1016/j.fuproc.2006.11.008

[28] Chen, D., Rebo, H.P., Moljord, K. and Holmen, A. (1997) The Role of Coke Deposition in the Conversion of Methanol to Olefins over SAPO-34. Studies in Surface Science and Catalysis, 111, 159-166. https://doi.org/10.1016/S0167-2991(97)80151-6

[29] Martínez, A., Peris, E., Derewinski, M. and Burkat-Dulakb, A. (2011) Improvement of Catalyst Stability during Methane Dehydroaromatization (MDA) on Mo/HZSM-5 Comprising Intracrystalline Mesopores. Catalysis Today, 169, 75-84. https://doi.org/10.1016/j.cattod.2010.11.063

[30] Kim, H.S., Lee, S.G., Kim, Y.H., Lee, D.H., Lee, J.B. and Park, C.S. (2013) Improvement of Lifetime Using Transition Metal-Incorporated SAPO-34 Catalysts in Conversion of Dimethyl Ether to Light Olefins. Journal of Nanomaterials, 2013, Article ID: 679758.

[31] Wen, D.F., Liu, Q., Fei, Z.Y., Yang, Y.R., Zhang, Z.X., Chen, X., Tang, J.H., Cui, M.F. and Qiao, X. (2017) Organosilane-Assisted Synthesis of Hierarchical Porous 
ZSM-5 Zeolite as a Durable Catalyst for Light-Olefins Production from Chloromethane. Industrial \& Engineering Chemistry Research, 57, 446-455.

https://doi.org/10.1021/acs.iecr.7b02332 